\title{
An easy method to introduce a bronchial blocker To the intended bronchus in pediatric patients
}

\section{Aihara S, Takashima A, Hashimoto C, Kamibayashi T, Hagihira S}

Department of Anesthesiology, Kansai Medical University, Hirakata City, Osaka, Japan

\section{Background}

It is rather technically difficult to introduce a bronchial blocker (BB) to the intended bronchus in pediatric patients, because the diameter of the trachea isn't enough wide to manipulate a fiber optic bronchoscopy (FOB) and a BB simultaneously. Here we introduced our easy method to achieve this. Our method is as follows.

At first, we intubated a proper size of tracheal tube (1-a) and advanced it into the intended bronchus with the aid of FOB (1-b). Then we introduced an Arndt巴 bronchial blocker to the intended bronchus through the tracheal tube (1-c). After that we once extubated the tracheal tube remaining the bronchial blocker in the bronchus (1-d). Finally, we intubated another tracheal tube, and adjust the position of a BB after fixed the patients position (1-e). This report is a case series.

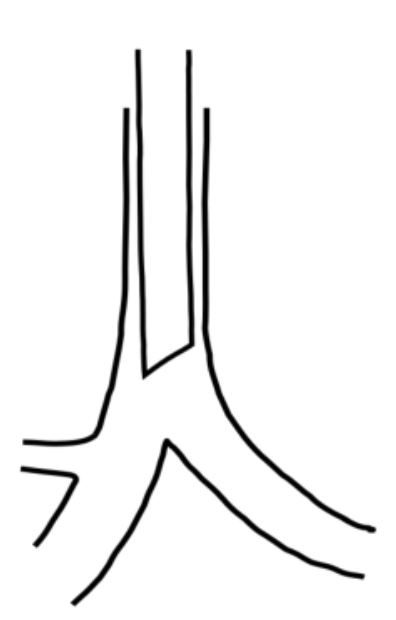

(a) intubation

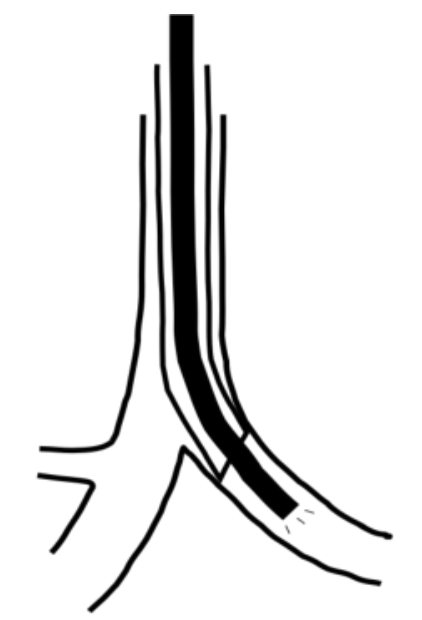

(b) bronchial intubation

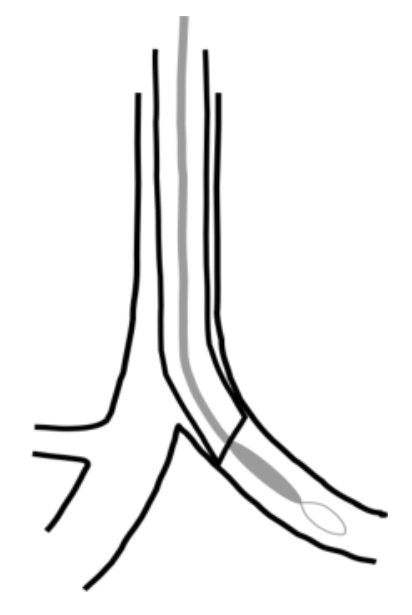

(c) BB insertion

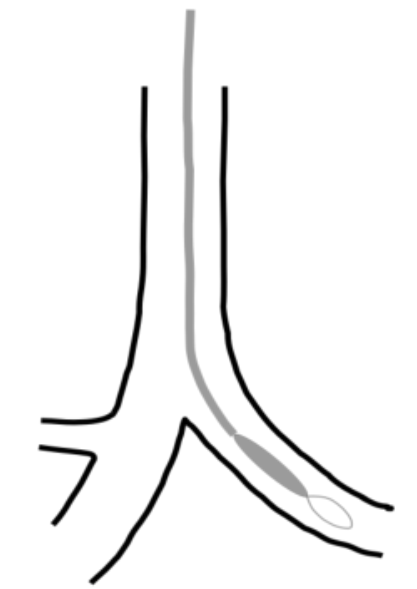

(d) extubation

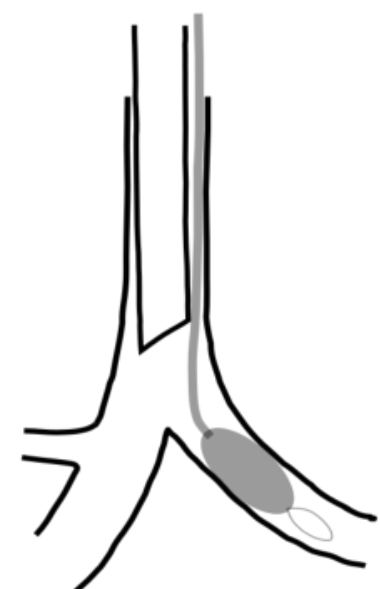

(e) re-intubation
Figure 1

\begin{tabular}{|r|r|r|r|r|l|l|r|}
\hline$\#$ & $\begin{array}{r}\text { Age } \\
(\mathbf{m})\end{array}$ & Gender & $\begin{array}{r}\text { Height } \\
(\mathbf{c m})\end{array}$ & $\begin{array}{r}\mathbf{B W} \\
\mathbf{( K g})\end{array}$ & \multicolumn{1}{|c|}{ Disease } & Operation & $\begin{array}{r}\text { Tube } \\
(\mathbf{m m})\end{array}$ \\
\hline 1 & 12 & male & 74 & 9.0 & Lt bronchial atresia & Lobectomy & 4.5 \\
\hline 2 & 6 & male & 63.8 & 6.2 & Rt mediastinal tumor & Resection & 3.5 \\
\hline 3 & 7 & male & 62 & 6.7 & Rt lower lobe CCAM & Lobectomy & 4 \\
\hline 4 & 4 & male & 68 & 6.5 & Rt lower lobe CCAM & Lobectomy & 4 \\
\hline 5 & 4 & male & 66.9 & 9.2 & Lt lower lobe CCAM & Lobectomy & 4 \\
\hline 6 & 6 & male & 66.4 & 7.4 & Lt lower lobe CCAM & Lobectomy & 4 \\
\hline 7 & 10 & female & 75 & 8.5 & Rt middle lobe CCAM & Lobectomy & 4 \\
\hline 8 & 14 & male & 76.5 & 10.4 & Lt bronchial atresia & Lobectomy & 4 \\
\hline 9 & 36 & male & 86.8 & 11.1 & Lt lower sequestration & Lobectomy & 4.5 \\
\hline
\end{tabular}

Table 1

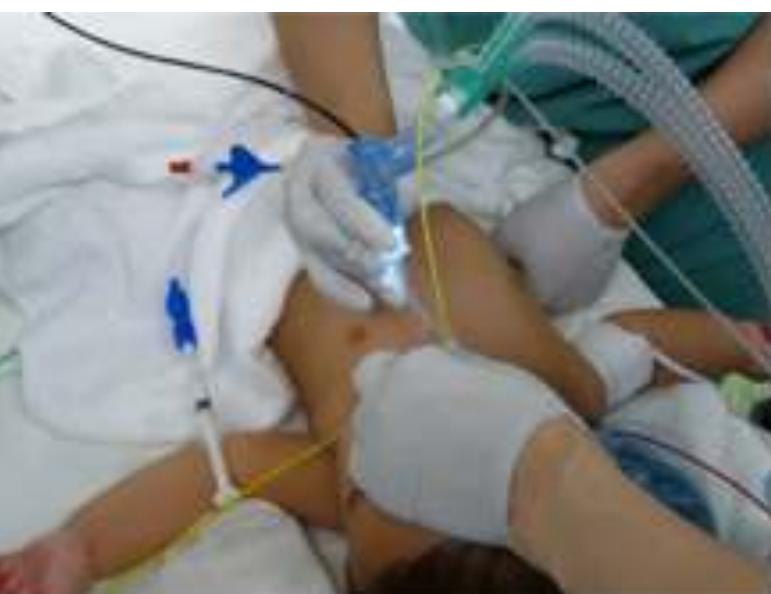

(a)

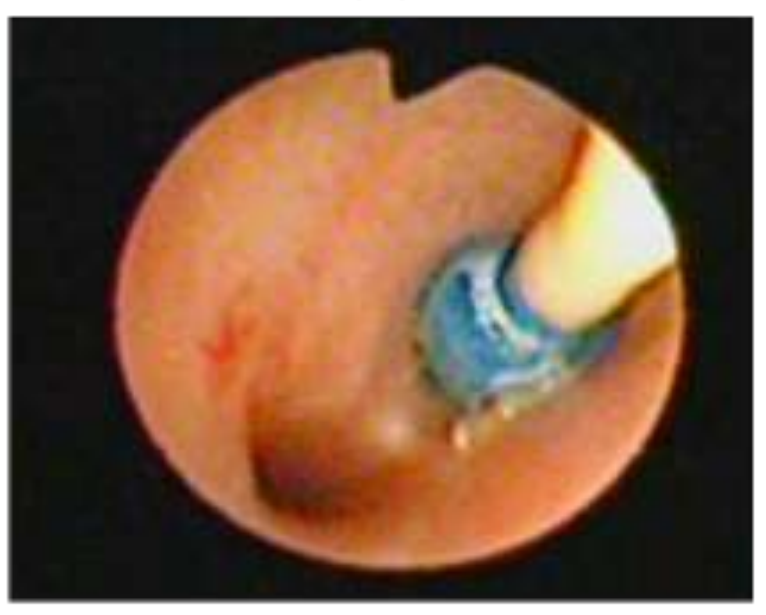

(c)

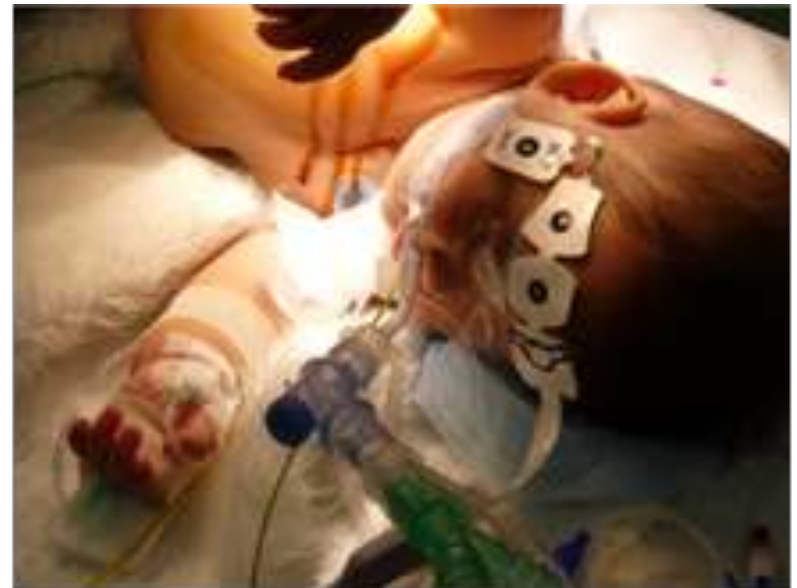

(b)

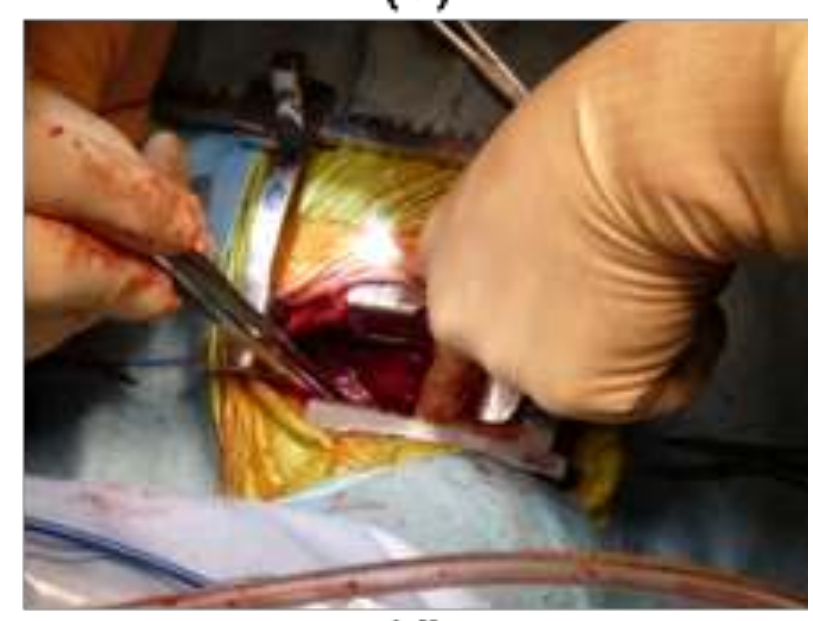

(d)
Figure 2

\section{Case Report}

We tried to apply our method to 9 pediatric cases (4 months to 3 years) as shown in Table 1 .

We adjust the position of a BB after fixed the patients position. (figure 2 - a to c) As shown in the Figure 2-d, isolated lung ventilation was successful (right side block).

In all cases, intubation to intended bronchus was easy (within 20 seconds), and BB could be advanced into the bronchus. After patients were placed in the lateral decubitus position, the position of BB was adjusted under FOB.

\section{Discussion}

An Arndt $\circledast$ bronchial blocker has a guide loop that enabled us to introduce the $\mathrm{BB}$ to the intended bronchus by FOB. However, manipulation of both $\mathrm{BB}$ and FOB is quite difficult or impossible in infant or small children because the diameter of a tracheal tube is not enough wide. With our method, introducing a BB to the intended bronchus is quite easy, and BB can be placed outside a tracheal tube, which made easier to handle FOB.

\section{Conclusion}

Our method presented here was quite effective to place a BB into the intended bronchus.

\section{Learning Points}

We recommend that we once intubate a tracheal tube into the intended bronchus and intorduce a BB, and extubate a tube then re-intubate another tracheal tube in pediatric cases. 